\title{
(2) OPEN ACCESS \\ Imagining the postantibiotic future: the visual culture of a global health threat
}

\author{
Rachel Irwin
}

Department of Arts and Cultural Sciences, Lund University, Lund, Sweden

\section{Correspondence to}

Dr Rachel Irwin, Arts and Cultural Sciences, Lund, Sweden: rachel.irwin@kultur.lu.se

Accepted 10 September 2020

\section{ABSTRACT}

This article is concerned with the visual culture of global health data using antimicrobial resistance (AMR) as an example. I explore how public health data and knowledge are repackaged into visualisations and presented in four contemporary genres: the animation, the TED Talk, the documentary and the satire programme. I focus on how different actors describe a world in which there are no or few antibiotics that are effective against bacterial infections. I examine the form, content and style of the visual cultural of AMR, examining how these genres tell a story of impending apocalypse while also trying to advert it. This is a form of story-telling based around the if/then structure: we are told that if we do not take certain actions today, then we will face a postantibiotic future with certain, often catastrophic, consequences. Within this if/then structure, there are various aims and objectives: the goal may be preventing further spread of AMR, building awareness or pushing for certain policy or funding decisions. These stories also serve to place or deflect blame, on animals, occupations, patients, industries and others and to highlight risks and consequences. These examples share similarities in the forms of story-telling and narrative, and in the use of specific data sources and other images. By using several Swedish examples, I demonstrate how global data are reinterpreted for a national audience. Overall, I argue that while the convergence of a dominant narrative indicates scientific consensus, this consensus also stifles our collective imagination in finding new solutions to the problem. Finally, I also use the example of AMR to discuss the need for a broader social science and humanities engagement with the visual culture of global health data.

A post-antibiotic era means, in effect, an end to modern medicine as we know it. Things as common as a strep throat or a child's scratched knee could once again kill.

-Dr Margaret Chan, former Director-General of the $\mathrm{WHO}^{12}$

Once global health data have been collected, cleaned and analysed, they are disseminated through reports, websites and various data visualisation tools. Well-known examples include the Global Burden of Disease's data visualisations or the work of the Gapminder Foundation, whose tagline is 'unveiling the beauty of statistics for a fact-based worldview'. In addition to visual representations of data, we also find photographs and illustrations accompanying the communication of research findings; these often are of Petri dishes or laboratory workers. Visualisations are further used in performances-for example, documentaries, YouTube presentations, animations, TED Talks and media interviews with or by researchers and policy makers; these images and performances are later interpreted and spread through mainstream media and social media platforms such as Instagram and Twitter. Through verbal cues and the visualisations, dominant stories about the nature of global health problems take shape.

This article is concerned with visual culture of global health data using the case of antimicrobial resistance (AMR). In the quote above from Dr Margaret Chan, the words are printed on an illustration of bacteria which I found through a Google image search and was hosted on Pinterest. The Pinterest image was, in turn, linked to an article on Medium.com, a Yahoo image search and a YouTube video. The quote itself comes from a speech given by Dr Chan in Copenhagen in 2012. This example highlights how data were collected and reported by the WHO; it was then used to describe what will happen in a postantibiotic future. This language was, in turn, used in images shared on and linked to a variety of digital platforms.

In this article I explore how public health data and knowledge are repackaged into visualisations and presented in a way that creates dominant narratives about the current state of AMR and perpetuates visions of a postantibiotic future. That is, I focus on how different actors describe a world in which there are no or few antibiotics that are effective against bacterial infections. ${ }^{3}$ I examine the form and content of the visual cultural of AMR, examining how performances are used to tell a story of an impending apocalypse while also trying to advert it. This is a form of story-telling based around the if/then structure: we are told that if we do not take certain actions today, then we will face a postantibiotic future with certain, often catastrophic, consequences: 'Modern medicine' will no longer be possible and we may find ourselves returning to the 'dark ages' of medicine.

Within this if/then structure, there are different audiences and purposes of visualisations. The goal may be preventing further spread of AMR, building awareness or pushing for certain policy or funding decisions. These stories also serve to place or deflect blame on animals, occupations (farmer, physician), patients, industries and others and to highlight risks, costs and other consequences. They are also often premised on 'antibiosis', or an antagonistic relationship between humans and microbes, which lends itself to metaphors around war. ${ }^{4}$ 
In the sections that follow, I first discuss how the visual culture of global health data can be approached in general terms. I then map the visual culture of AMR, describing my own methods in doing so. Finally, I look in detail at four contemporary genres of the postantibiotic apocalypse: the animation, the TED talk, the documentary and the satire programme. These genres can be seen as meta-sources in that they use multiple visualisations and images from different sources as evidence to advance their arguments. Furthermore, the examples I present from these four genres share similarities in the forms of story-telling and narrative, the use and sharing of specific data sources, and the ways in which data and public health knowledge are used in performances that imagine a postantibiotic future. By using several Swedish examples, I also demonstrate how global data are reinterpreted for a national audience. Overall, analysing the visual culture, rather than text alone, demonstrates how imagery serves to reinforce existing narratives and metaphors, and to influence how different audiences make sense of data.

\section{THE VISUAL CULTURE OF GLOBAL HEALTH DATA: FROM DATA TO PERFORMANCE}

As a starting point, global health data include counts, and more complicated metrics such as ratios and composite indicators. Numbers are often reported as neutral facts-either by the organisations that create them or by the media's coverage; and they are assumed to be created by expert knowledge. This assumption of facts as neutral evidence is a depoliticising move. ${ }^{5678}$ Yet there are a number of norms, values and assumptions inherent in the entire process, from the creation of data collection tools, to the development of databases and reporting. ${ }^{9101112}$ For instance, data points are made commensurable-that is, the wider historical, social and cultural context of each point is stripped away, so that it can be combined with other data points and incorporated into reports on global trends.

The practices of data entry also constrain and create knowledge. ${ }^{1314}$ Data have to meet certain formats or standards to be published, and they may be 'cleaned' to fit the format. Even the aesthetics of forms also influence how users fill them in and how researchers carry out data entry; and information can be lost in translation. For example, it can happen that a disease outbreak occurs in an Arabic-speaking country, but the reporting form is in English. In the process of recording the outbreak location a mistake can be made in spelling which, in turn, means that one village can be mistaken for another village. In the case of AMR, simply defining and counting AMR is complicated, and many of the extrapolations and projects on its burden are based on limited or contested data. ${ }^{1516}$

Once global health data have been collected, cleaned and analysed, they are often turned into data visualisations. Global health data are reported in annual reports filled with photos and different types of data visualisations. These might include reports by the WHO, as well as national health agencies, such as from Public Health England or the Public Health Agency of Sweden (Folkhälsomyndigheten). Representations also feature in online spaces. A well-known example is the Global Burden of Disease Study's website which 'provides a dazzling interface with a slew of data visualisation tools, education modules, and interactive interfaces that produce spectacular charts, maps, and tables'. ${ }^{17}$ Another example is Our World in Data and the SDG-Tracker, based at the University of Oxford. These are two websites, run by the same team, which present data and research on global challenges-that is, poverty, health, population, along with progress on the Sustainable Development Goals (SDGs).
Here we also see performative aspects of data presentation and use. ${ }^{18} 19$ For instance, Gapminder data are used in a performance in which a presenter stands on stage and uses data visualisations to explain the state of the world in a structured pageant of story-telling. These visualisations are shared widely, often on social media, and used to provide a representation of the state of global health. Complementary to these types of sites, performances are also found in YouTube videos and on Twitter, Instagram and other social media.

Social media engagement is a performative act, and the sharing of visualisations or graphs serves to communicate and to persuade. These textual and graphical representations, alongside language, endorse a certain ordering of experience and narrative; they also endorse certain truths about the state of the world. This is particularly the case with infographics, which present data and an explanation. That is, the interaction of iconography and narrative reinforce each other and serve to persuade the viewer of the message. ${ }^{20}{ }^{21}$ Furthermore, social media engagement also moves health issues from the expert domain into the public one, in which public health topics become 'recontextualised, transformed, and disseminated as political and cultural topics as well'.22

The way in which data are handled, displayed and performed matters for three reasons: metrics are used as governance tools, they give rise to different networks and they are used to promote certain worldviews. As governance tools, metrics influence action. ${ }^{23}{ }^{24}$ Governmental funding decisions may be made based on the prevalence of a disease. Conversely, if the data are not judged to be 'robust' or 'reliable', this may constrain political options. This is also a form of biopower, in the Foucaldian sense, in that data dictate how populations are 'constructed' or 'seen' and defined as 'being in need' or as targets for intervention. ${ }^{25} \mathrm{In}$ AMR, an extension of this is how bacteria and microbes become 'things' to count and control. ${ }^{26}$ Another example of these political aspects arises from the lack of AMR data, as noted above. Clare Chandler has used Andrew Lakoff's work to examine how AMR transitions from an actuarial problem to a sentinel one. That is, because it is difficult to define and measure AMR, the scale of the problem becomes 'inferred, rather than known'. However, due to the 'sentiment of the need for action', the discourse turns to projecting $\mathrm{AMR} .^{27}$ As Chandler notes, various governmental and intergovernmental reports simultaneously 'allude to the "lack of data" while emphasising a "certain threat". That is, numbers, in the form of projections, are needed to justify action. In this way, rather than AMR as a current, countable problem, it becomes framed within an 'anticipatory logic', as a problem-inthe-making if we do not act now. ${ }^{28}$

Second, metrics give rise to networks of organisations and actors: entire transnational communities are created at this intersection of counting, documenting and reporting, creating what Christina Garsten and Anette Nyqvist have called a 'legitimised social grouping. ${ }^{29}$ These social fields include experts in data collection, and individuals—such as graphic designers-responsible for the visual displays of quantitative information. ${ }^{30}$ In turn, their work on the collection and interpretation, and aesthetics of data contributes to changes in global health practice. Many of these individuals are employed by international organisations, which shape the world through the production of authoritative knowledge, in the form of official figures and statistics. ${ }^{3132}$ Additionally, different organisations collect and present data in vastly different ways, depending on their mandate, structure and history; and conceptually, data are interpreted through organisational norms and values. 


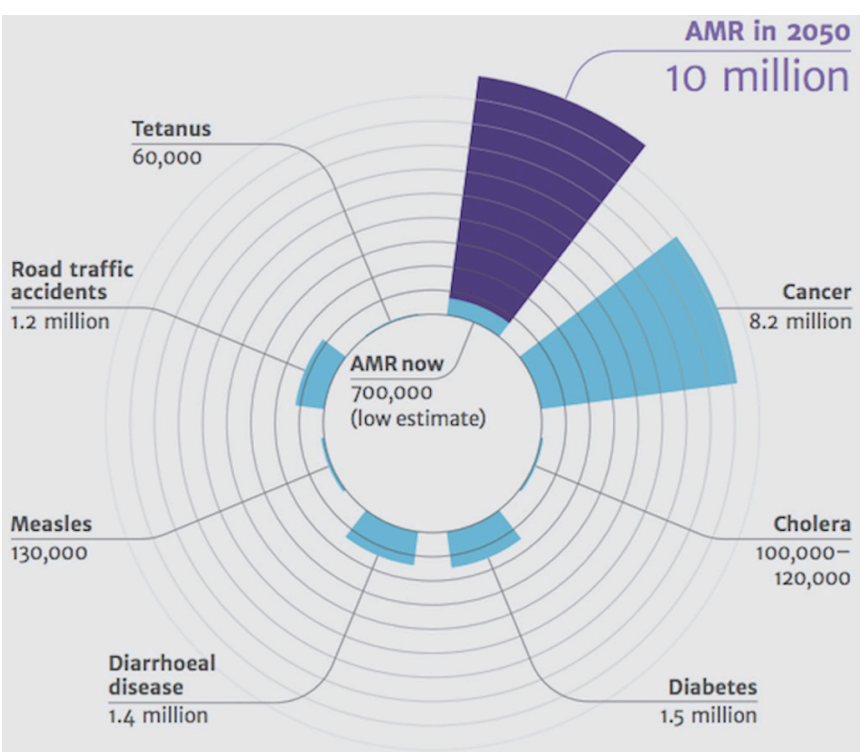

Figure 1 Rose chart on forecast deaths from antimicrobial resistance (AMR), AMR Review, 2014.

Finally, as alluded to above, metrics work is a form of storytelling that affects our worldview. ${ }^{24}$ Story-telling should not be considered inherently negative. On a very practical level, for instance, well-designed infographics play an important role in health communication, and can also serve to engage viewers. ${ }^{33}$ However, the pitfalls of power and authoritative knowledge are obvious here. The presentation of data with visually oriented language, graphics and data visualisations are used to develop global narratives about the causes of and solutions to global issues, and to perform a narrative about the nature of reality. ${ }^{34}$ ${ }^{35}$ As an example, one of the most watched TED Talks is Hans Rosling's aptly titled 'Let my data change your mindset' from 2009..$^{36}$

The concept of imaginary is particularly useful in understanding AMR story-telling. Writing of global health in general, Herrick and Reubi describe imaginaries as " "normatively loaded" and "often complex visions of the world" that shape agendas, projects, policies and behaviours in the field'. They represent 'visions' that 'bring together and exist through intricate constellations of moral narratives, scientific theories, administrative practices and architectural spaces that both enable and constrain thought and action'. ${ }^{37}$

The storyline of AMR as a public health problem often focuses on inappropriate or 'irrational' use of antibiotics, overprescribing by physicians or inappropriate demand by patients. This leads to solutions that focus on raising awareness of the problem, changing individual behaviour or developing new antibiotics, often via market-based solutions. ${ }^{3839}$ Brown and Nettleton discuss economic imaginaries: how economic metaphors used to conceptualise AMR mechanisms, consequences and causes can partly explain how a focus on market failures became part of the explanatory tapestry of AMR. ${ }^{40}$ The speculative nature of the AMR threat, combined with an antibiosis perspective, further lends itself to the use of metaphors from the financial sector, as well as to security and war metaphors. ${ }^{41}$ Furthermore, imaginaries of catastrophic, apocalyptic, postantibiotic futures offer insights into the anxieties of modernity. That is, these may, for instance, be concerns over our relationship with technology, in the form of antibiotics and 'modern' medicine. ${ }^{42}$ Taking the visualisations as a starting point, I return to the key question of this article: how does the performance of data, with the use of rhetoric and visualisations, give rise to or reinforce a collective imagination about what will happen if we do not act to prevent a certain health issue?

\section{MAPPING THE (DIGITAL) VISUAL CULTURE OF THE POSTANTIBIOTIC FUTURE}

I write this article from the perspective of critical global health, an interdisciplinary space, largely dominated by international relations and anthropology, but which also includes history, sociology, geography, science and technology studies and other disciplines. ${ }^{43}$ Despite their ubiquity, there remains a need to further investigate the visual culture of global health data. In doing so, I draw inspiration from visual studies, art history and the digital humanities, and related interdisciplinary fields that have looked at visual rhetoric, narrative and political uses with regard to data visualisations, as well as how data are shared on social media. ${ }^{44} 45464748$

While the life course of a data visualisation is complex, the scope of this article is limited to one aspect: how data are communicated to an informed lay audience through still and moving images. I focus on the period from 2014 to 2020. In 2014 the WHO released 'Antimicrobial resistance: Global Report on Surveillance'. In USA, the Report to the President on Combating Antibiotic Resistance was also published in 2014. The same year 'Antimicrobial Resistance: Tackling a crisis for the health and wealth of nations' (the AMR Review) was commissioned by then UK Prime Minister David Cameron and the Wellcome Trust, with the final report released in 2016. In 2015, the World Health Assembly (WHA) - the WHO's supreme governing body-endorsed the Global Action Plan on Antimicrobial Resistance. These were landmark documents, with the data and graphics widely shared, particularly the AMR Review rose chart on forecast deaths from AMR (figure 1). This is not to say that AMR was not discussed globally before then, but rather that it gained significant attention through these reports making the time period from 2014 particularly salient for my analysis. $^{49}$

In mapping the visual culture of AMR, I focused on sources in English and Swedish. With the exception of two TED Talks which I analyse, most of the images come out of the UK and/or Sweden. Scandinavia has come 'to serve as a global model for antibiotic stewardship, reflecting longstanding attention to antibiotics as precious resources'. ${ }^{50}$ In the past decade both Sweden and the UK have been two of the most politically active counties on a global level. For example, at the sixty-seventh WHA in 2014 Sweden and the UK co-sponsored WHA Resolution 67.25 on AMR and in 2016 the countries co-hosted a high-level meeting on AMR. Looking at how AMR is communicated to a lay audience in politically active countries provides an interesting case.

Using Google Images search I used terminology around AMR to look for images, including 'antibiotic resistance' 'antimicrobial resistance' and 'post-antibiotic future'; I searched YouTube with the same terms. I also searched Twitter using the hashtags: \#AMR, \#Antimicrobialresistance and \#Antibioticresistance. The internet is a vast space and my intention was not to systematically or comprehensively search for all images, but to explore the online space and qualitatively map the themes and trends. I also focused on ways in which the future is predicted and visualised.

This research was done without patient involvement. Patients were not invited to comment on the study design and were not consulted to develop patient-relevant outcomes or interpret the 
results. Patients were not invited to contribute to the writing or editing of this document for readability or accuracy.

This visual material largely includes graphs that show projections or forecasts of increased antibiotic resistance and also infographics and animations that explain the causes of and solutions to AMR. These are found in reports by and on websites of international and national authorities such as the WHO, the European Centre for Disease Control, Public Health England and many others. Many visualisations are hosted by individual researchers, the pharmaceutical industry and civil society. There is also a substantial non-expert space online. For instance, the YouTube channel 'Answers with Joe' has 739000 subscribers and the 2019 video 'Are we on the Verge of A Post-Antibiotic World?' has almost 150000 views. ${ }^{51}$ By contrast, Public Health England's YouTube channel has 4280 subscribers and their 2014 video 'What is antibiotic resistance?' has 25000 views. ${ }^{52}$

Visual material is shared by researchers and public health professionals, and the public on platforms such as Instagram and Pinterest. The issue is also debated in online forums: for example, using the example of Mumsnet.com, Nik Brown and Sarah Nettelton have analysed the dominant discourses through which antibiotics, immunity and resistance are debated. ${ }^{53}$ Antibiotic resistance also is discussed in the pseudoscience spaces, such as the website Goop.

In this mapping, several key themes emerge. First, data visualisations, images and visual language need to be understood in relationship to each other. Visual language is used by politicians and diplomats in settings such as the annual World Economic Forum in Davos or the WHA. These include statements such as the one by Margaret Chan at the beginning of this article-this is language to describe what would happen if we do not act now.

This is also found in news media, such as the July 2019 article in The Economist imaging it was the year 2041 with the title 'If Antibiotics stop working. Attack of the superbugs: July 2041'. 54 Similarly, in virtually all YouTube videos on AMR the presenter uses speech, data visualisations and images to explain what a postantibiotic future will look like.

Second, I found that certain data sets, images and visualisations become dominant in their circulation; the key example of this is the statistic from the 2014 AMR Review that there could be 10 million deaths from AMR by 2050 . This features in most performances of AMR data (figure 1). This is a reflection of the shift in actuarial framing to sentinel framing, and, as the dominant projection, serves a symbolic function in that it stands in for projected fears about AMR and the economy.

Third, one often finds a repackaging of global data for a national or local audience. For instance, the Canadian Broadcasting Corporation had a news report in which they presented the WHO's 2014 report 'Antimicrobial resistance: Global Report on Surveillance, ${ }^{55}$ In framing the report, they interviewed experts to discuss the scope and nature of the issue in the Canadian context and the need for better responses at the individual, healthcare and national levels. This also comes up in other television clips, including from daytime programmes. In another example, AMR and the relationship between the global and Swedish contexts features regularly on presenter Malou von Siver's daytime talk show programme Malou Efter Tio (Malou after 10:00).

Finally, key metaphors and framings emerge and re-emerge. The catastrophic and apocalyptic frame is common, as are the related war metaphors. ${ }^{56}$ An example is the February 2020 issue of Swedish magazine Forskning och Framsteg (Research and Progress) with a photo of a Petri dish and the headline 'A ticking timebomb: antibiotic resistance - how Swedish researchers are fighting back'. One also finds language employing economic and capitalist images, further drawing on economic imaginaries. ${ }^{57}$ These metaphors are tied to the ways in which the problem is framed and messaged. ${ }^{58}$ In the next section I look in more detail at how four genres use data visualisations, images, metaphors and framings to describe what will happen if we do not advert a postantibiotic future.

\section{FOUR GENRES OF THE POSTANTIBIOTIC APOCALYPSE The animation}

There is a range of animations about AMR on the internet. Some, like the WHO's 'Amala's Story: how to prevent antimicrobial resistance', start with a fictional story about a baby with a bacterial infection. ${ }^{59}$ This is interspersed with explanations of what resistance is, including animations of bacteria as monsters before returning to Amala's fate. Other animations add movement to a textbook-style graphic. For instance, the US Food and Drug Administration produced a short video, demonstrating the mechanisms of resistance. ${ }^{60}$ This shows antibiotics moving through a cell wall, attaching to enzymes and stopping DNA replication.

Others take the form of a moving infographic, drawing on metaphorical representations. For example, a TED-Ed animation starts with tanks standing in for antibiotics. ${ }^{61}$ These are shooting projectiles at a fire-breathing dragon who stands in for 'infectious disease'. Later we see anthropomorphised bacteria throwing grenades. The voice-over goes on to describe the invention of antibiotics, showing a cartoon of Alexander Fleming (discoverer of penicillin) in a tank, and then it discusses overuse, disincentives for the pharmaceutical industry and the use of antibiotics in agriculture.

One of the most iconic animations comes from Action on Antibiotic Resistance, better known as ReAct. ReAct is an international network set up in Sweden in 2005 with the goal "to be a global catalyst, advocating and stimulating for global engagement on antibiotic resistance." ${ }^{62}$ Today ReAct Europe is hosted at Uppsala University in Sweden. ReAct and Uppsala University host an online course called 'Antibiotic Resistance - the Silent Tsunami', for which they commissioned a short animation about the history and the current status of antibiotics. ${ }^{63}$ It is just under 3 min long. Certainly, a short animation cannot be expected to cover the complexities of antibiotic resistance (and the animation is also meant as an advertisement for the online course), but it does provide a good introduction to the issue.

The animation starts with the history of antibiotics and resistance, and we are told that 'the bacteria have fought back'. It shows a time line of the discovery of specific antibiotics and when resistance to them was discovered. 'Thousands of deaths' are represented by cartoon gravestones. The voice-over describes the causes: unnecessary prescriptions and over-the-counter sales of antibiotics, although it notes that lack of access kills more people in low-income and middle-income countries than resistance. Other causes include poor infection control in hospitals and international travel and trade. The voice-over tells us 'the unpleasant truth is that scientists have not come up with a new class of antibiotic since 1987'. As such 'we are about to enter an era in which many commonly used antibiotics have lost their affects'. As 'modern medicine' relies on the availability of effective antibiotics, organ transplants, chemotherapy, and common surgeries such as hip replacements, will become 'too risky'. We are told that 'resistance is costly'.

Then, citing figures from the AMR Review they use a graveyardthemed animation (figure 2) to tell us that by 2050, the number 


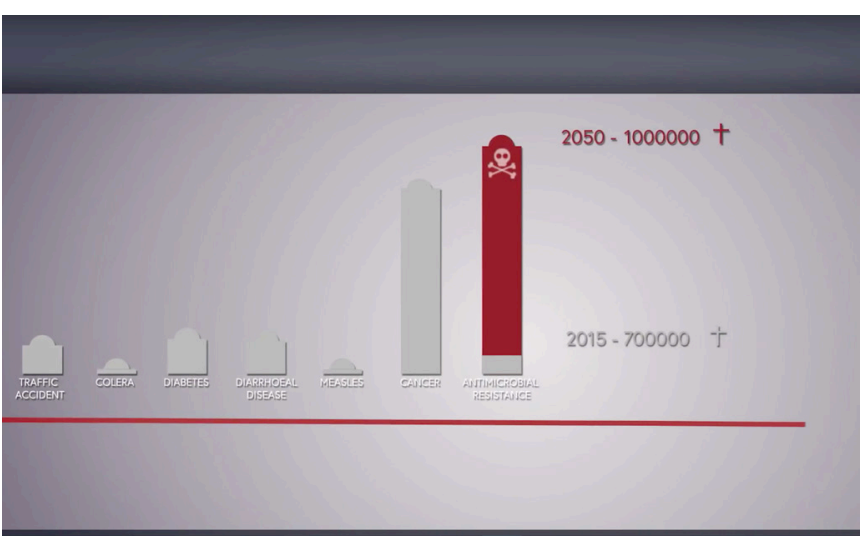

Figure 2 The Silent Tsunami, visual lab (www.visuallab.no), commissioned by ReAct and Uppsala University.

of deaths from antibiotic resistance could reach 10 million per year, and thus exceed the number of people who die annually of cancer today.

The animation concludes by asking 'are we heading towards a post-antibiotic era?' and telling us that 'while we cannot reverse this frightening trend, but we can slow it down. And all of us need to change our behaviour'.

\section{The TEDx talk}

TED (Technology, Entertainment and Design) is a 'nonprofit devoted to spreading ideas, usually in the form of short, powerful talks' of $18 \mathrm{~min}$ or less. It was founded as a conference in 1984 but since then has expanded into a 'viral video phenomenon' and has launched spin-offs, such as TEDx. ${ }^{64}$ On one hand, TED Talks can be seen as democratising in that they are open-access and widely available. The genre also allows for researchers to increase their own visibility and distribute findings outside of academia. One the other hand, they have been criticised for presenting a simplified, reality-show version of complex social and political issues. Regardless, as a genre they both reflect and reproduce dominant discourses. ${ }^{65}$

AMR is a popular TED subject, with over 40 TED, TEDx and other spin-off videos on the subject. I focus here on Maryn McKenna's TED Talk 'What do we do when antibiotics don't work anymore?' which was given in Vancouver in 2015 and has 216165 views on YouTube. ${ }^{66}$ I also touch on TEDx talks by Kevin Judice at Southern Methodist University in Texas, ${ }^{67}$ Fredrik Almqvist at Umeå University in Sweden ${ }^{68}$ and Linus Sandegren at Uppsala University. ${ }^{69}$

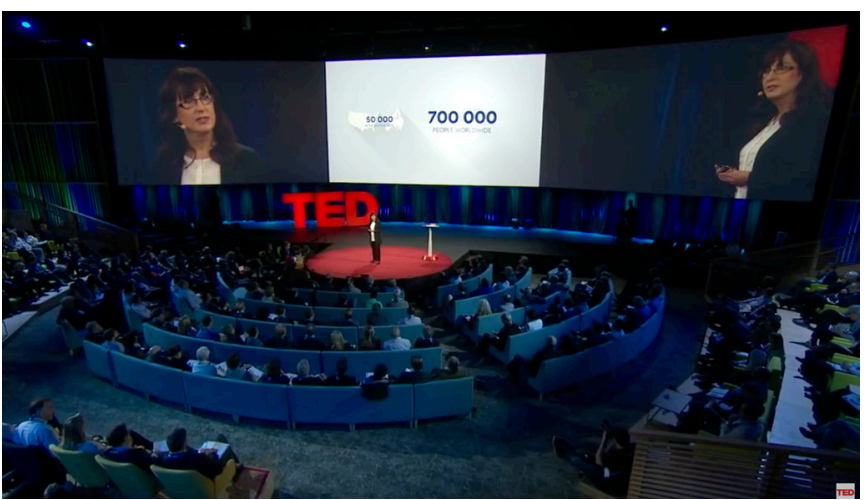

Figure 3 Maryn McKenna @ TED, 2015.
McKenna starts with a personal story of her great uncle who died of an infection in 1938. She uses visual language to tell us that 'if you look back through history, most people died like my uncle died... they died of infections after being gored by an ox, shot on a battlefield or crushed in one of the new factories of the industrial revolution'. She warns us that 'we stand today on the threshold of the post-antibiotic era'.

She describes resistance in terms of 'competition', 'attack' and 'asymmetric warfare', and she walks us through the spread of antibiotic resistance. She shows time-lapse maps: Klebsiella pneumoniae carbapenemase resistance (KPC) spreading across the USA and New Delhi metallo-beta-lactamase 1 (NDM) spreading from India to Sweden (via a traveller), and then across the world. At several points she refers to the AMR Review, telling us that 700000 people die each year from AMR and that by 2050 it could be 10 million a year (figure 3 ).

She reminds us that antibiotics 'support almost all of modern life', and would affect the immunocompromised and make organ transplants, implanted medical devices, surgeries and other procedures impossible:

We'd lose the confident way we live our everyday lives. If you knew that any injury could kill you, would you ride a motorcycle, bomb down a ski slope, climb a ladder to hang up Christmas lights, let your kid slide into home plate.

She tells us that 'we did this by squandering antibiotics', and discusses their misuse. In healthcare this includes over-thecounter sales of antibiotics and the prescribing of antibiotics for conditions that do not warrant them. She also notes the use of antibiotics in the food industry.

She concludes with solutions. New incentives for pharmaceutical companies to develop new antibiotics are needed, as are better data and computer-based technical solutions for improved surveillance. She then turns to individual behaviour stating that 'antibiotic resistance is a habit' and comparing it to littering, smoking and not wearing seat belts. She tells us that we need to change social norms and to 'stop insisting on a prescription for our kids ear infection until we're sure what caused it'.

Similar themes and visualisations are found in the other talks. Judice starts by telling us that in order to understand the coming 'post-antibiotic era', we need to understand the preantibiotic era, which he describes with a story of a girl who nearly died of a staphylococcus infection in 1942 before being treated with penicillin. Similar to McKenna's KPC and NDM maps, he also shows a time-lapse map of the spread of carbapenem-resistant Enterobacteriaceae spreading through the USA. He also concludes with a personal story of his son who recovered after a bacterial infection. Almqvist begins his talk with photos of Alexander Fleming and Gerhard Domgk (discoverer of sulfonamidochrysoidine). He also uses the O'Neill report graphic (figure 1) along with a photo of the giant agar dish from a study by Baym et al in Science, referring to agar as a 'smörgåsbord' for bacteria. ${ }^{70}$ Sandegren also begins with photos of Fleming and tells us that 'we need to use antibiotics in a rational way'. While these talks focus on individual solutions to the issue-Almqvist tells us, we shouldn't 'push physicians' to write prescriptions - they also focus on the need for new antibiotics and innovative approaches to fighting bacteria. Both Judice and McKenna suggest acting as consumers and asking restaurants and supermarkets to provide antibioticfree meat. 


\section{The documentary}

The Swedish national broadcaster Sveriges Television (SVT) broadcast the documentary Antibiotics to death (Antibiotika till döds) as part of the series Vetenskapens värld in Autumn 2019. This was a Swedish edit of the 2019 BBC One documentary 'The Truth About ... Antibiotics' presented by Angela Rippon. ${ }^{71}$

${ }^{72}$ In the repackaging, the Swedish host shortly introduces the documentary with the line 'bacteria are sly (sluga) and they've learnt to survive - and many of them have learnt to survive our antibiotic cures'. This reflects a similar comment we hear later on by Angela Rippon that 'bacteria are clever little so-and-sos. They have learnt how to become resistance to antibiotics'. Additionally, the English-language voice-over was replaced by a Swedish one, and after the documentary was finished, the host interviewed a Swedish expert for comment and mentioned a few facts about AMR in Sweden, not least that sales of antibiotics had decreased in Sweden by 19\% since 2000.

In the main documentary, presenter Angela Rippon starts with a personal narrative of suffering from tuberculosis as a child and the importance of streptomycin in her recovery. Throughout the documentary she meets other people who have suffered personally because of AMR. The documentary then presents photos and videos of people living normal lives, hospitals, livestock, labs and nature before reminding us-with the data from the AMR Review-that if we do not act now, ' 10 million people could die every year - more than from cancer'.

The documentary relies on a number of visual metaphors. Bowling balls are 'antibiotics' which take out bacteria, represented by bowling pins. The 'race' for antibiotics is described as a competition between bacteria and humans, and is represented by rely runners who then drop the pin when they come to the 1980s. A child who throws out a basket with one rotten apple and many healthy apples demonstrates how broad spectrum antibiotics affect our biome.

The most striking visual metaphor is one in which 60 extras stand in a square, representing the population of Great Britain. The voice-over tells us that 'almost half of them could die if there weren't antibiotics'. As Angela Rippon walks through the square while knocking over people, the voice-over tells us these deaths could be caused by the lack of access to caesarean sections, care for preterm babies, chemotherapy, and routine surgeries such as hip and knee replacements. At the end of the visual metaphor, Rippon stands in the square and tells us that 'before antibiotics, $40 \%$ of us would die from infection (figure 4 ). Without antibiotics we are going to return to the dark ages of medicine when even a simple scratch could be a death sentence'.

The documentary goes through the causes of AMR and we see Baym et al's giant agar plate again. Rippon then investigates

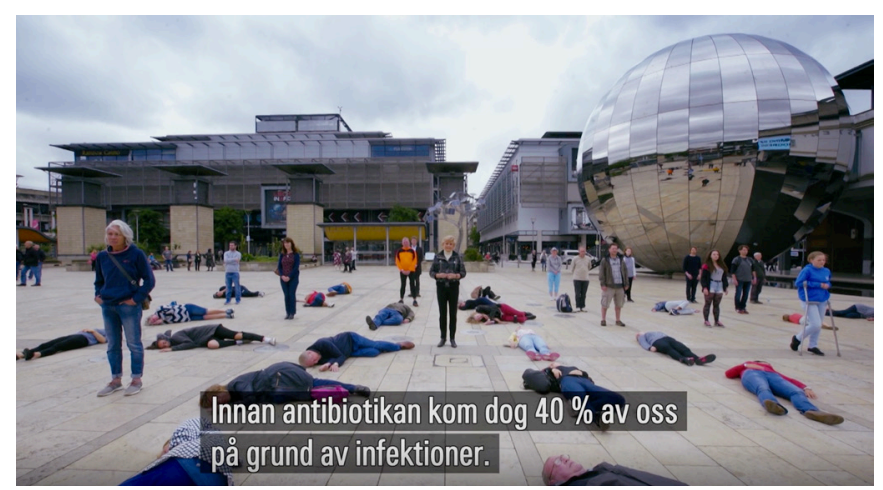

Figure 4 The truth about ... antibiotics, BBC 2019. a number of individual and collective solutions. Individual solutions include addressing patient over and misuse, and there is a scene on the importance of handwashing. More collective solutions, such as improved hospital routines, better diagnostic tools and the search for new antibiotics are also covered. The documentary stands out among other media in that it also covers the use of bacteriophages, or phages. Bacteriophages are viruses that attack bacteria and their discovery predates antibiotics; while they remain in use in many post-Soviet countries, they are rarely used in the so-called West. She visits Dr Ben Chan at Yale who researches phages, as well as the UK patient who imported bacteriophages from Georgia. She also meets with the then UK Chief Medical Officer, Dame Sally Davies, to discuss the market failure of antibiotic development: pharmaceutical companies have little incentive to go through a long and costly process to create a medicine that will be rarely used. Rippon concludes that a new funding model is needed, and that government and companies need to work together. Finally, at the end, Rippon warns us that we need to stop 'sleepwalking into an apocalypse'.

\section{The satire programme}

Svenska Nyheter (Swedish News), modelled after American news satire programmes debuted in 2018. In January 2020, they had a $10 \mathrm{~min}$ piece on AMR which featured several clips from material I have already discussed. ${ }^{73}$

The segment begins with a joke about how bacteria are 'happy' that we are focusing our attention on Coronavirus because we are not paying attention to them. In setting the scene, a series of images are shown. First there is a photo of Alexander Fleming. This is followed by a clip from (Swedish) TV4 News which has a voice-over as someone is working in a lab. The host, Kristoffer Appelquist, notes that AMR is on the WHO's list of Ten Threats to Global Health in 2019 and also that Alexander Fleming had warned of this in the 1940s. Appelquist then uses an animation of an aeroplane dropping ciprofloxacin bombs onto Escherichia coli bacteria to describe how resistance arises (figure 5), and also works in a pun about Colin Nutley, an English director who works in Sweden (E. coli becomes E-Coli Nutley).

Appelquist then notes that antibiotic resistance would not have developed so quickly if we hadn't 'wasted' antibiotics. To make this point, he shows a clip from the Swedish Médecins Sans Frontières (MSF)'s YouTube channel which, in turn, has a video from Norwegian MSF. In this video, the chairperson of Norwegian MSF describes the use of antibiotics in livestock. Appelquist responds with 'Do you understand how messed up (sjukt) it is that antibiotics - medicines that we should be restrictive with - are used to make healthy animals grow faster?' He then uses an example of a hypothetical conversation between a father and daughter:

Daughter: Daddy, why did we speed up the development of resistant bacteria?

Father: Because we wanted yummier pork chops (fläskkotletter) Daughter: Is that why mummy is dead?

Father: Yes, but do you remember the funeral fika - what a scrumptious bacon cake (bacontårta) we had!

Appelquist tells us that if we do not address AMR it means in the future-or even today, you can die of common infections such as urinary tract infections (UTIs), pneumonia or even a small infected shaving cut. He then shows a clip from the Silent Tsunami with the gravestone visualisation (figure 2). He warns that 'We are on the way back to a time before penicillin was discovered, when one could die of a paper cut'. He then says 


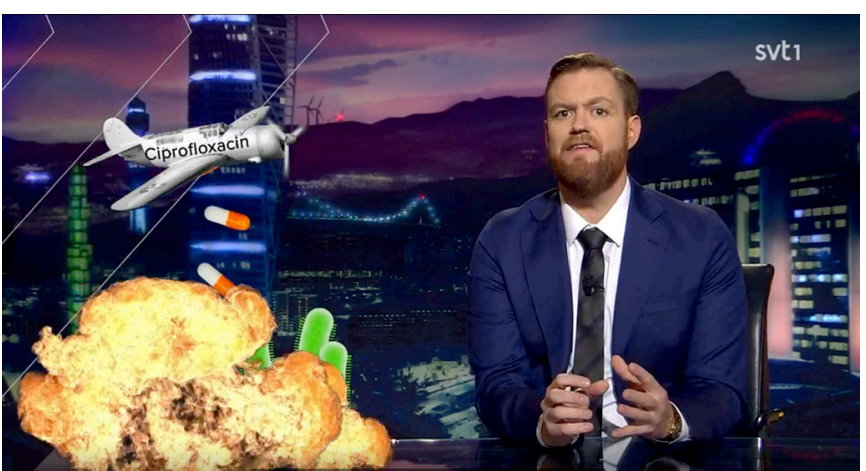

Figure 5 Svenska Nyheter (Swedish news), Sveriges Television (SVT) 2019.

that this is not a scary future scenario, but something that is happening now and cites figures that each year about 33000 die in Europe and 150-200 in Sweden from AMR:

Today resistance is of course much more of a problem in the rest of the world than in Sweden.

But it doesn't matter how well we behave (sköter oss) here in Sweden, because bacteria are - like Putin - really bad (skitdåliga) at respecting borders.

He describes food importation as risk to Sweden, and also notes that Swedes travel a lot in South-East Asia and can bring back resistant bacteria as souvenirs. He shows a 2017 clip from the daytime programme Malou Efter Tio in which a doctor states that up to $90 \%$ of Swedish travellers to India or Vietnam bring back resistant bacteria in their guts (while showing a WHO-sourced map of estimated deaths connected to antibiotic resistance by 2050). Appelquist also uses the risk of international travel to make a series of jokes about Jonas Sjöstedt, who had recently stood down from leader of the Left Party (Vänsterpartiet) to join his family in Vietnam, where his wife is the Swedish Ambassador.

Although Appelquist only shows a short clip from Malou Efter Tio, it is worth taking a detour to look at this segment in detail. Host Malou von Sivers is joined by Dr Johan Kaarme and Pernilla Nånting, whose daughter died of a resistant infection. ${ }^{74}$ The starting point is a new study by Dr Kaarme. ${ }^{75} \mathrm{He}$ wears scrubs, perhaps as signifier of expertise, which also gives the appearance that he needs to rush off to the hospital as soon as he finishes with Malou. They talk about the issue and also look at the map. In one exchange:

Malou von Sivers: It's like we'll return to how things were, that one can die of pneumonia or a simple blood poisoning, things that we take for granted (that we can cure) today.

Dr Kaame: Today in the world, and partially even in Sweden where we are good (duktig) as you say - because we are - antibiotics are used when they shouldn't be.

Returning to Svenska Nyheter, Appelquist uses the scene with Dame Sally Davies from Vetenskapens värld/The Truth About ... Antibiotics on why there is not enough investment in new antibiotics. Appelquist then puts forward the argument that there is a role for taxpayer's money and state intervention, and he cites a new Swedish research project that was promising until it ran out of money. He ends with 'So what can you do? Don't complain to your doctor that you want antibiotics' and 'we need to get the rest of the world to listen before it is too late'.
The show ended with Beata Ernman singing, to the tune of Edith Piaf's Non, Je ne regrette rein:

You are going to die

You are all going to die

From sores

From pus

From anthrax, typhus and TWAR $^{1}$

Boils and gonorrhoea

You can have penicillin

But you'll die - regardless of medicine!

\section{DISCUSSION}

Focusing on these four genres, we find many similarities in the story-telling and the way in which data serve as a basis for performance. Within the examples discussed, the same images, sets of data and data visualisations circulate. Time-lapse maps show the spread of resistance. The giant agar plate from the 2016 Baym et al study features in several TEDx Talks and the Vetenskaps värld/BBC documentary. The stories of researchers like Fleming and Domgk teach the public about the beginnings of AMR. Broadly, we see images of people in labs, Petri dishes and microscopic photos of bacteria. This kind of visual framing of the story provides a collective starting point for the public to understand what AMR looks like.

From this starting point, the narrative structure of the genres is based on a definition of the problem and discussion of the solution. There are specific narrative arcs, often relating to if/ then statements and solutions in which the preantibiotic era is used to imagine the postantibiotic era. This is the idea that, if we do not act now, then we will return to an era in which paper cuts will kill. In some, personal stories-such as Angela Rippon's or those in Maryn McKenna's TED Talk-are used to add weight to the seriousness of the situation. In this way, the framing device of 'imagine a world ...,' often found in science fiction, is used to drive the narrative. ${ }^{76}$ By inviting us to imagine a catastrophic future, the dominant metaphors invoke fears over the 'end of modern medicine' and the potential 'return to the dark ages of medicine'.

The preantibiotic era is further constructed through language and images. We are told that bacteria have fought back, and we face the terrifying prospects of 'sleepwalking into an apocalypse' in which anthrax, typhus and gonorrhoea will be untreatable. Common medical procedures will no longer be possible, and people will die. There are also similar aesthetic conventions and metaphors in the genres: bacteria are 'clever': they are monsters with agency, and we need to fight them. Animations of bacteria as monsters offer visual representations of antibiosis, justifying the use of war metaphors.

The same data sources also become part of the collective consciousness and in many ways the rose chart from the AMR Review has come to stand for the problem caused by AMR (figure 1). This estimate, that AMR could cause 10 million deaths a year by 2050 , 'has become a familiar refrain ..., quoted repeatedly by lay media, experts, and public health agencies'. ${ }^{77}$ This is despite the fact that there are significant problems with the calculations, projections and underlying data collection used in this number. ${ }^{78}$ However, in the absence of concrete figures, 
'the 10 million deaths a year by 2050 ' is the sentinel projection turned mantra which calls for action.

We also see how these same data are repackaged and interpreted for a national or local audience. Humorously, this is accomplished in the Svenska Nyheter piece by using AMR to make jokes about politicians and Swedish celebrities, or in Almqvist's TEDx Talk when he refers to agar as a 'smörgåsbord' for bacteria. Less benign is the focus on AMR as something that comes from outside of Sweden. This is the idea that 'No matter how good or responsible (duktig) we are in Sweden, it is a global problem that still affects us'. Indeed, the trope that disease comes from abroad is one of the oldest in health, and the idea of the 'foreign' comes up in Brown and Nettleton's analysis of Mumsnet.

Overall, there is a dominant view of what causes antibiotic resistance and how it can be averted. This largely focuses on behaviour change in the healthcare setting, by both prescribers and patients, along with the development of new drugs. ${ }^{79}$ Again, the simplification of the narrative is not inherently bad: science communication is about engaging with viewers and clearly explaining complex information. ${ }^{80}$ Within AMR, the use of a clear narrative is not by chance: cognisant of the scepticism over climate change, the broader global health community has learnt the importance of clear and consistent messaging. ${ }^{81}$ However, there are limitations of this approach. One is that many solutions are individual based which is what Chandler has referred to as the paradox in AMR: it is a 'problem of connectedness to be solved by individualised action'. This focus on the individual's responsibility to forego antibiotics can overlook the wider structural context and the use of antibiotics in, for instance, food production or the inappropriate disposal of waste from pharmaceutical companies, often in lowincome and middle-income countries. The dominant focus on incentivising pharmaceutical companies to produce new antibiotics through marked-based solutions also has its limits. While antibiotics play a role, there are many other solutions such as vaccines, essential oils and natural compounds, bacteriophages, disinfectants and improved biosecurity measures, although these other solutions also have drawbacks. ${ }^{82}$

Again, we return to the dominant metaphor that we are 'standing on the threshold of a post-antibiotic era'. This catastrophic framing is seductive for several reasons. First, in a defence for the 'postantibiotic apocalypse', James notes that metaphors remain useful in the public communication of science. ${ }^{83}$ Similarly, it is exciting and drives the story. ${ }^{84}$ Third, the catastrophic framing speaks to something deeper about societal stress. In this case, AMR can be seen as a threat to and a fight for modernity, and 'a canvass for the projection of wider existential insecurities'. ${ }^{85} 86$

However, the catastrophic frame can also lead to inaction or desensitisation. ${ }^{87}$ Comparing climate change science to AMR, Nerlich asks whether or not catastrophic language helps or hinders: 'Do people feel empowered to do something, or do they just feel powerless and do not act; attention grabbing vs fear? ${ }^{98}$ The catastrophic frame also sidesteps material transitions in the world. That is, the notion that we will all die of infections if we do not have antibiotics ignores changes in risk factors: being gored by an ox is not a risk factor in twenty-first-century Vancouver. The bacteria of today have different genetic characteristics of the bacteria of the preantibiotic era. ${ }^{89}$ It also ignores that scientific knowledge and hygiene have improved immensely since the discovery of penicillin. This is not to suggest a progressive notion of science and society, but rather to suggest that the future will not look exactly like that past.

Several researchers have suggested other frames, metaphors and ways of making sense of our relationship to bacteria that can be more useful. Greenhough et al have called for a transition from the
Western, antibiosis paradigm to a focus on balance with microbiota. Similarly, using the example of a video game, Servitje suggested moving from war metaphors to a model of coexistence. ${ }^{90}$ Speaking against simplistic framings around individualistic and/or marketbased solutions, Hinchliffe et al, call for AMR to be 'framed as an adaptive, rather than technical challenge'. ${ }^{91}$ Broom et al have proposed a 'solidaristic model' which also moves way from a focus on the individual to viewing AMR as a 'systemic problem that is structured by the complex interplay of social, political, and economic forces, and institutional practices such as metrics'.

\section{CONCLUSIONS}

While images are ubiquitous in global health, as researchers our main form of communication is the written word. This article is a reminder that visualisation is part of discourse, and that visualisations provide a bridge between academia and the so-called informed public, through online videos, documentaries, social media and various genres. Here we see a complex visual culture of global health data, with a mosaic of data visualisations, textually reported statistics and photographs used together in the performance of data. In this case, the 'beauty of data', often in the form of time-lapse maps or projections-turned-mantras, such as the ' 10 million' gloss over the ambiguities of data collection and handling, and combine with other types of images and words, to promote a certain worldview about AMR.

The fact there is a convergent narrative about the causes of and solutions to AMR indicates a degree of scientific and political consensus. However, our collective imagination on what will happen if we do not act-that is, the consensus on what a postantibiotic future looks like is limited. While the past provides a basis for imaging the future, the future is not the past. The postantibiotic era will not be the same as the preantibiotic era. These images constrain our imaginations in looking for alternative solutions, ways of living and the strategies to address and prevent a postantibiotic apocalypse. However, in looking for new ways of understanding AMR, we need to find metaphors that are simple to understand, visualisable and engaging.

Acknowledgements The author thanks Coll de Lima Hutchison and Kristofer Hansson for their comments.

Contributors $\mathrm{Rl}$ is the sole author.

Funding This study was funded by Pufendorf Institute for Advanced Study and the Department of Arts and Cultural Sciences, Lund University.

Competing interests None declared.

Patient and public involvement Patients and/or the public were not involved in the design, or conduct, or reporting, or dissemination plans of this research.

Patient consent for publication Not required.

Provenance and peer review Not commissioned; externally peer reviewed.

Data availability statement Data are available in a public, open access repository. Most of the data are publicly available on YouTube or other online platforms. Video from Swedish Television (SVT) is available to researchers upon request.

Open access This is an open access article distributed in accordance with the Creative Commons Attribution Non Commercial (CC BY-NC 4.0) license, which permits others to distribute, remix, adapt, build upon this work non-commercially, and license their derivative works on different terms, provided the original work is properly cited, appropriate credit is given, any changes made indicated, and the use is non-commercial. See: http://creativecommons.org/licenses/by-nc/4.0/.

\section{ORCID iD}

Rachel Irwin http://orcid.org/0000-0002-8350-441X

\section{NOTES}

1. Taiwan Acute Respiratory Agent "post-antibiotic future," Pinterest photo, accessed February 25, 2020, https://pin.it/hDOsDIR 
2. Margaret Chan, "Antimicrobial resistance in the European Union and the World." Speech in Copenhagen on March 14, 2012, accessed February 25, 2020, https://www. who.int/dg/speeches/2012/amr_20120314/en/

3. Antibiotics are only one type of antimicrobial, and it is important to avoid conflating the the two terms. The empirical material with which this article is concerned mainly relates to antibiotics, but much of the social theory discussed attends to antimicrobials in general. For this reason, I use both terms in the article.

4. Helen Lambert, Meixuan Chen, and Christie Cabral (2019), "Antimicrobial resistance, inflammatory responses: a comparative analysis of pathogenicities, knowledge hybrids and the semantics of antibiotic use." Palgrave Communications, 5, no.85 (2019).

5. Vicanne Adams (2016), Metrics: What Counts in Global Health (Durham, NC: Duke UP, 2016).

6. Martin Gorsky and Christopher Sirrs (2017), "World health by place: the politics of international health system metrics, 1924-c. 2010," Journal of Global History, 12, no. 3 (November 2017): 361-85. https://doi.org/10.1017/S1740022817000134

7. Birgit Müller (2013), "Introduction," in The Gloss of Harmony: The Politics of PolicyMaking in Multilateral Organisations, ed. Birgit Müller (Chicago: University of Chicago Press, 2013).

8. Peter Andreas and Kelly M. Greenhill (2011), "Introduction" In Sex, Drugs, and Body Counts. The Politics of Numbers in Global Crime and Conflict, edited by Peter Andreas and Kelly M. Greenhill,(Ithaca: Cornell UP, 2011).

9. Katerini T Storeng and Dominique P Béhague (2017), "'Guilty until proven innocent': the contested use of maternal mortality indicators in global health," Critical Public Health, 27, no. 2 (2017):163-76. https://doi.org/10.1080/09581596. 2016.1259459

10. Adams, Metrics: What Counts in Global Health.

11. Andreas and Greenhill, "Introduction".

12. Sally Engle Merry (2016), The Seductions of Quantification (Chicago: University of Chicago Press, 2016).

13. Helene Ratner and Evelyn Ruppert (2019), "Producing and Projecting Data: Aesthetic Practices of Government Data Portals," Big Data \& Society. 6, no.2 (2019). https://doi. org/10.1177\%2F2053951719853316

14. Geoffrey C Bowker and Susan Leigh Starr (1999), Sorting Things Out. Classification and Its Consequences. (Cambridge, MA: MIT Press, 1999).

15. Clare Chandler, 2020, "Current accounts of antimicrobial resistance: stabilisation, individualisation and antibiotics as infrastructure," Palgrave Communications 5, no. 53 (2020),

16. Marlieke E A de Kraker, Andrew J Stewardson, and Stephan Harbarth (2016). "Will 10 Million People Die a Year due to Antimicrobial Resistance by 2050?" PloS Medicine. 13, no. 11 (2016) doi:10.1371/journal. pmed. 1002184.

17. Manjari Mahajan (2019), "The IHME in the Shifting Landscape of Global Health Metrics," Global Policy. 1, Supp 1 (2019):110-20. https://doi.org/10.1111/1758-5899. 12605

18. Merry, The Seductions of Quantification.

19. Stefan Ecks (2008), "Three propositions for an evidence-based medical anthropology," JRAI 14, no. SI (2008);s77-s92. https://doi.org/10.1111/j.1467-9655.2008.00494.x

20. Sue Walker (2019). "Effective antimicrobial resistance communication: the role of information design, Palgrave Communications," 5, no.24 (2019).

21. Lorenzo Servitje (2019). "Gaming the Apocalypse in the Time of Antibiotic Resistance," Osiris, 31, no. 1(2019):316-37.

22. David Serlin (2010). "Introduction. Towards a visual culture of public health. From Broadside to YouTube," In Imagining IIIness: Public Health and Visual Culture. Minneapolis: University of Minnesota Press. 2010.

23. Merry, The Seductions of Quantification.

24. Adams, Metrics: What Counts in Global Health.

25. Lauren Carruth (2018). "The Data Hustle: How Beneficiaries Benefit from Continual Data Collection and Humanitarian Aid Research in the Somali Region of Ethiopia," Medical Anthropology Quarterly. 32, no.3 (2019): 340-364. https://doi.org/10.1111/ maq. 12431

26. Beth Greenhough et al. (2018). "Unsettling antibiosis: how might interdisciplinary researchers generate a feeling for the microbiome and to what effect?" Palgrave Communications, 4, no. 149 (2018).

27. Chandler 2020.

28. Poldolsky, 2019.

29. Christina Garsten and Annette Nyqvist (2013) Organisational anthropology: doing ethnography in and among complex organisations (New York: Pluto Press, 2013).

30. Edward E Tufte (1983), The Visual Display of Quantitative Information. Cheshire, CT: Graphics Press, 1983.

31. Garsten and Nyqvist, Organisational anthropology.

32. Müller, "Introduction."
33. Sue Walker (2019). "Effective antimicrobial resistance communication: the role of information design, Palgrave Communications," 5, no.24 (2019).

34. Kevin Davis et al. (2012). Governance by indicators: global power through quantification and rankings. (Oxford: Oxford University Press, 2012).

35. Davis et al, Governance by indicators.

36. Tobias Denskus and Daniel E. Esser (2015), "TED Talks on International Development: Trans-Hegemonic Promise and Ritualistic Constraints," Communication Theory 25 (2015):166-87. doi:10.1111/comt.12066.

37. Clare Herrick and D David Reubi (2017). Global Health and Geographical Imaginaries. (Routledge, 2017).

38. Steve Hinchliffe, Andrea Butcher, and Muhammad Meezanur Rahman (2018). The AMR problem: demanding economies, biological margins, and co-producing alternative strategies. Palgrave Communications 4, no. 142 (2018).

39. Chandler 2020

40. Nik Brown and Sarah Nettleton (2018). "Economic imaginaries of the Anti-biosis: between 'economies of resistance' and the 'resistance of economies,' " Palgrave Communications, 4, no.123 (2018).

41. Chandler 2020.

42. Brian Brown and Paul Crawford (2009). "'Post-antibiotic apocalypse.' Discourses of mutation in narratives of MRSA," Sociology of Health \& Illness 31, no. 4 (2009) $508-24$.

43. Clare Herrick and David Reubi, D, eds. Global Health and Geographical Imaginaries. (Routledge, 2017).

44. Roopika Risam (2019), "Beyond the Migrant 'Problem': Visualizing Global Migration," Television \& New Media. 20, no. 6 (2019):566-80, https://doi.org/10.1177\% 2F1527476419857679

45. Paul Dourish and Edgar Gómez Cruz (2018), "Datafication and data fiction: Narrating data and narrating with data," Big Data \& Society, 5, no.2 (July-December 2018), https://doi.org/10.1177\%2F2053951718784083

46. Rosemary Lucy Hill (2017), "The political potential of numbers: data visualisation in the abortion debate," Women, Gender and Research/Kvinder, Køn \& Forskning. 26, no.1 (2017):83-96.

47. Helen Kennedy et al. (2016), " Engaging with (big) data visualisations. Factors that affect engagement and resulting new definitions of effectiveness," First Monday. 21, no. 11 (2016)

48. Eedan R Amit-Danhi and Limor Shifman (2018), "Digital political infographics: A rhetorical palette of an emergent genre," New Media and Society, 20, no. 10, (2018): 3540-3559. https://doi.org/10.1177\%2F1461444817750565

49. Scott H Poldolsky (2018), "The evolving response to antibiotic resistance (19452018)," Palgrave Communications, 4, no.124(2018). https://doi.org/10.1057/s41599018-0181-x

50. Poldolsky, "The evolving response".

51. Joe Scott, "Are we on the verge of a post-antibiotic world?," YouTube video posted April 22, 2019, accessed February 25, 2020, https://www.youtube.com/watch?v= iExWBTDe6Eg

52. Public Health England, "What is antibiotic resistance?," YouTube video posted September 18, 2014, accessed February 25, 2020, https://www.youtube.com/watch? $v=7$ PhmyNBWGik

53. Nik Brown and Sarah Nettleton (2017), "Bugs in the blog: Immunity moralism in antimicrobial resistance (AMR)," Social Theory and Health 15 (2017): 302-22. https:// doi.org/10.1057/s41285-017-0030-9

54. "If Antibiotics stop working. Attack of the superbugs: July 2041," The Economist, July 6, 2019.

55. Canadian Broadcasting Corporation, "World headed for 'apocalyptic' post-antibiotic era," YouTube video posted April 30, 2014, accessed February 25, 2020, https://www. youtube.com/watch?v=A1NwPGN24vl

56. Brigitte Nerlich (2009). "'The post-antibiotic apocalypse' and the 'war on superbugs': catastrophe discourse in microbiology, its rhetorical form and political function," Public Understanding of Science, 18, no.5 (2009): 574-90.

57. Brown and Nettleton, "Bugs in the blog".

58. Chandler, "Current accounts".

59. WHO, "Amala's Story: how to prevent antimicrobial resistance," YouTube video posted on May 8, 2018. Accessed July 21, 2020

60. US FDA, "Animation of Antimicrobial Resistance." YouTube video posted on Nov 9, 2017, accessed July 21, 2020.

61. Wright, Gerry, "How can we solve the antibiotic resistance crisis?" TED-Ed video posted on YouTube on March 16, 2020, accessed July 21, 2020.

62. "About us," ReAct, accessed February 25, 2020, https://www.reactgroup.org/about-us/ 63. ReAct and Uppsala University, "Silent Tsunami," YouTube video posted on September 2, 2016, accessed February 25, 2020. 
64. "About us," TED, accessed February 25, 2020, ted.com.

65. Denskus and Esser, "TED talks".

66. Maryn McKenna: What do we do when antibiotics don't work any more?," TED Talk posted on YouTube June 25, 2015, accessed February 25, 2020, https://www.youtube. com/watch?v=030DpCb7Vql

67. Kevin Judice, "Life in the post-antibiotic era is going to suck," TEDxSMU Talk posted on YouTube, November 12, 2014, accessed February 25, 2020, https://www.youtube.com/ watch? $\mathrm{v}=\mathrm{YHiMsoj} 3 \mathrm{XH \textrm {K }}$

68. Fredrik Almqvist, "Turning the tide of antimicrobial resistance." TEDxUmeå Talk posted on YouTube July 11, 2017, accessed February 25, 2020, https://www.youtube.com/ watch?v=-idjbjkrHeM

69. Linus Sandegren, "Why bacteria out-evolve us with antibiotic resistance." Accessed February 26, 2020, https://www.youtube.com/watch?v=etg9tFv-P6Q

70. Michael Baym et al. (2016), "Spatiotemporal microbial evolution on antibiotic landscapes," Science 353, no.6304 (2016) :1147-51. https://dx.doi.org/10.1126\% 2Fscience.aag0822

71. BBC One, "The truth about ... antibiotics," accessed February 25, 2020, https://www. bbc.co.uk/programmes/b0c1nl68

72. Vetenskapens värld, "Antibiotika till döds," accessed February 25, 2020, https:// www.svtplay.se/video/24287177/vetenskapens-varld/vetenskapens-varld-sasong-31antibiotika-till-dods?info=visa\&start=auto

73. Svenska Nyheter, accessed February 25, 2020, https://www.svtplay.se/video/ 25258363/svenska-nyheter/svenska-nyheter-sasong-5-31-jan-22-00?start=auto

74. Malou efter tio, "Antibiotikaresistens ökar dramatisk hos förskolebarn," accessed February 25, 2020, https://www.youtube.com/watch?v=nkjgm0CQjjkhttps://www. youtube.com/watch?v=nkjgm0CQjjk

75. Johan Kaarme, "The world inside:" Gastrointestinal microbiota in healthy Swedish children at day care centres and aspects on antibiotic resistance, enteric pathogens and transmission. Uppsala: Acta Universitatis Upsaliensis, 2017. https://uu.diva-portal. org/smash/get/diva2:1056157/FULLTEXT01.pdf

76. Lorenzo Servitje (2019). "Gaming the Apocalypse in the Time of Antibiotic Resistance," Osiris, 31, no. 1(2019):316-37.

77. De Kraker, "Will 10 Million People Die?"

78. De Kraker, "Will 10 Million People Die?"

79. Alex Broom et al. (2020). "Antimicrobial resistance as a problem of values? Views from three continents," Critical Public Health. Online first (2020).

80. Walker, 2019.

81. Chandler, "Current accounts".

82. R.R Bragg et al. (2015), "Potential Treatment Options in a Post-antibiotic Era," in Infectious Diseases and Nanomedicine III, eds. Rameshwa Adhikari and Santosh Thapa, (Springer, 2015), 51-62. https://link.springer.com/chapter/10.1007\%2F978-981-107572-8_5

83. James in Nerlich 2009.

84. Servitje, 2019.

85. Chandler 2020

86. Brown and Nettleton 2017.

87. Servitje, 2019.

88. Nerlich 2009.

89. Hannah Landecker. Antibiotic resistance and the biology of history," The New Biologies, 22, no.4 (2016):19-52.

90. Servitje, 2019.

91. Hinchliffe et al, 2018

\section{BIBLIOGRAPHY}

Adams, Vicanne. Metrics: What Counts in Global Health. Durham, NC: Duke UP, 2016

Amit-Danhi, Eedan R, and Limor Shifman. "Digital political infographics: a rhetorical palette of an emergent genre." New Media \& Society 20, no. 10 (2018): 3540-59.

Andreas, Peter, and Kelly M. Greenhill. "Introduction" In Sex, Drugs, and Body Counts." In The Politics of Numbers in Global Crime and Conflict, edited by Peter Andreas, and KellyM Greenhill. Ithaca: Cornell UP, 2011.

Baym, Michael, Tami D Lieberman, Eric D Kelsic, Remy Chait, Rotem Gross, Idan Yelin, and Roy Kishony. "Spatiotemporal microbial evolution on antibiotic landscapes." Science 353, no. 6304 (2016): 1147-51.

Bowker, Geoffrey C, and Susan Leigh Starr. Sorting Things Out. Classification and Its Consequences. Cambridge, MA: MIT Press, 1999.

Bragg, R.R., C.M. Meyburgh., J-Y Lee, and M. Coetzee. "Potential Treatment Options in a Post-antibiotic Era." In Infectious Diseases and Nanomedicine III, edited by Rameshwa Adhikari, and Santosh Thapa, 51-62: Springer, 2015.

Broom, Alex, Katherine Kenny, Barbara Prainsack, and Jennifer Broom. "Antimicrobial resistance as a problem of values? views from three continents." Critical Public Health 5, no. 1 (2020): 1-13.
Brown, Brian, and Paul Crawford. "'Post antibiotic apocalypse': discourses of mutation in narratives of MRSA." Sociology of Health \& IIIness 31, no. 4 (2009): 508-24.

Brown, Nik, and Sarah Nettleton. "Bugs in the blog: Immunitary moralism in antimicrobial resistance (AMR)." Social Theory \& Health 15, no. 3 (2017): 302-22.

Brown, Nik, and Sarah Nettleton. "Economic imaginaries of the Anti-biosis: between 'economies of resistance' and the 'resistance of economies'." Palgrave Communications 4, no. 1 (2018).

Carruth, Lauren. "The data Hustle: how beneficiaries benefit from continual data collection and humanitarian aid research in the Somali region of Ethiopia." Medical Anthropology Quarterly 32, no. 3 (2018): 340-64.

Chandler, Clare. "Current accounts of antimicrobial resistance: stabilisation, individualisation and antibiotics as infrastructure." Palgrave communications 5, no. 53 (2020).

Davis, Kevin., Angelina Fisher., Benedict Kingsbury, and Sally Engle Merry. Governance by indicators: global power through quantification and rankings. Oxford: Oxford University Press, 2012.

de Kraker, Marlieke E A, Andrew J Stewardson, and Stephan Harbarth. "Will 10 million people die a year due to antimicrobial resistance by 2050?" PLOS Medicine 13, no. 11 (2016), e1002184.

Denskus, Tobias, and Daniel E. Esser. "Ted talks on international development: TransHegemonic promise and Ritualistic constraints." Communication Theory 25, no. 2 (2015): 166-87.

Dourish, Paul, and Edgar Gómez Cruz. "Datafication and data fiction: Narrating data and narrating with data." Big Data \& Society 5, no. 2 (2018): 205395171878408.

Ecks, Stefan. "Three propositions for an evidence-based medical anthropology." JRAI, no. 14 (2008): s77-92.

Garsten, Christina, and Annette Nyqvist. Organisational anthropology: doing ethnography in and among complex organisations. New York: Pluto Press, 2013.

Gorsky, Martin, and Christopher Sirrs. "World health by place: the politics of international health system metrics, 1924-c. 2010." Journal of Global History 12, no. 3 (2017): 361-85.

Greenhough, Beth, Andrew Dwyer, Richard Grenyer, Timothy Hodgetts, Carmen McLeod, and Jamie Lorimer. "Unsettling antibiosis: how might interdisciplinary researchers generate a feeling for the microbiome and to what effect?" Palgrave Communications 4, no. 1 (2018).

Herrick, Clare, and D David Reubi. Global Health and Geographical Imaginaries: Routledge, 2017.

Hill, Rosemary Lucy. "The political potential of numbers: data visualisation in the abortion debate." Kvinder, Køn \& Forskning 26, no. 1 (2017): 83-96.

Hinchliffe, Steve, Andrea Butcher, and Muhammad Meezanur Rahman. "The AMR problem: demanding economies, biological margins, and co-producing alternative strategies." Palgrave Communications 4, no. 1 (2018).

Kennedy, Helen, Rosemary Lucy Hill, William Allen, and Andy Kirk. "Engaging with (big) data visualisations. factors that affect engagement and resulting new definitions of effectiveness." First Monday 21, no. 11 (2016).

Lambert, Helen, Meixuan Chen, and Christie Cabral. "Antimicrobial resistance, inflammatory responses: a comparative analysis of pathogenicities, knowledge hybrids and the semantics of antibiotic use." Palgrave Communications 5, no. 1 (2019).

Mahajan, Manjari. "The IHME in the shifting landscape of global health metrics." Global policy 1, no. 1 (2019): 110-20.

Merry, Sally Engle. The Seductions of Quantification. Chicago: University of Chicago Press, 2016.

Müller, Birgit. "Introduction." In The Gloss of Harmony: The Politics of Policy-Making in Multilateral Organisations, edited by Birgit Müller. Chicago: University of Chicago Press, 2013.

Nerlich, Brigitte. " The post-antibiotic apocalypse" and the "war on superbugs": catastrophe discourse in microbiology, its rhetorical form and political function." Public Understanding of Science 18, no. 5 (2009): 574-90.

Poldolsky, Scott H. "The evolving response to antibiotic resistance (1945-2018)." Palgrave communications 4, no. 124 (2018).

Ratner, Helene, and Evelyn Ruppert. "Producing and projecting data: aesthetic practices of government data portals." Big Data \& Society 6, no. 2 (2019): 205395171985331.

Risam, Roopika. "Beyond the Migrant "Problem": Visualizing Global Migration." Television \& New Media 20, no. 6 (2019): 566-80

Serlin, David. Introduction. Towards a visual culture of public health. From Broadside to YouTube. In Imagining IIIness: Public Health and Visual Culture. Minneapolis: University of Minnesota Press, 2010.

Servitje, Lorenzo. "Gaming the Apocalypse in the time of antibiotic resistance." Osiris 34, no. 1 (2019): 316-37.

Storeng, Katerini T, and Dominique P Béhague. " "Guilty until proven innocent": the contested use of maternal mortality indicators in global health." Critical Public Health 27, no. 2 (2017): 163-76.

Tufte, Edward E. The Visual Display of Quantitative Information. Cheshire, CT: Graphics Press, 1983.

Walker, Sue. "Effective antimicrobial resistance communication: the role of information design, Palgrave communications." 5, no. 24 (2019). 